\title{
Synthesis and Crystal Structure of the Bioinorganic Complex $[\mathrm{Sb}($ Hedta $)] \cdot 2 \mathrm{H}_{2} \mathrm{O}$
}

\author{
Di Li and Guo-Qing Zhong \\ State Key Laboratory Cultivation Base for Nonmetal Composite and Functional Materials, School of Material Science and Engineering, \\ Southwest University of Science and Technology, Mianyang 621010, China
}

Correspondence should be addressed to Guo-Qing Zhong; zgq316@163.com

Received 31 October 2013; Revised 12 December 2013; Accepted 15 December 2013; Published 13 February 2014

Academic Editor: Concepción López

Copyright (C) 2014 D. Li and G.-Q. Zhong. This is an open access article distributed under the Creative Commons Attribution License, which permits unrestricted use, distribution, and reproduction in any medium, provided the original work is properly cited.

\begin{abstract}
The antimony(III) complex [ $\mathrm{Sb}(\mathrm{Hedta})] \cdot 2 \mathrm{H}_{2} \mathrm{O}$ was synthesized with ethylenediaminetetraacetic acid ( $\mathrm{H}_{4}$ edta) and antimonous oxide as main raw materials in aqueous solution. The composition and structure of the complex were characterized by elemental analysis, infrared spectra, single crystal X-ray diffraction, X-ray powder diffraction, thermogravimetry, and differential scanning calorimetry. The crystal structure of the antimony(III) complex belongs to orthorhombic system, space group Pna2(1), with cell parameters of $a=18.4823(18) \AA, b=10.9408(12) \AA, c=7.3671(5) \AA, V=1489.7(2) \AA^{3}, Z=4$, and $D_{c}=1.993 \mathrm{~g} \mathrm{~cm}^{-3}$. The $\mathrm{Sb}$ (III) ion is five-coordinated by two amido $\mathrm{N}$ atoms and three carboxyl $\mathrm{O}$ atoms from a single Hedta ${ }^{3-}$ ligand, forming a distorted trigonal bipyramid geometry. The thermal decomposition processes of the complex include dehydration, oxidation, and pyrolysis of the ligand, and the last residue is $\mathrm{Sb}_{2} \mathrm{O}_{3}$ at the temperature of $570^{\circ} \mathrm{C}$.
\end{abstract}

\section{Introduction}

Many of the antimony(III) compounds have been mainly used in the clinic medicine because of their medicinal utility and biological activity. The aminopolycarboxylate complexes of antimony(III) with effective antimicrobial and anticancer activity are widely applied to the treatment of a variety of microbial infections including leishmaniasis, diarrhea, peptic ulcers, and helicobacter pylori, and so forth $[1,2]$. The ethylenediaminetetraacetic acid as one of the multicarboxylate ligands possesses diverse functional groups such as $\mathrm{N}$ donor and O-donor. When a metal ion is in the center position, the ligand is always allowed to bend and to rotate, and one can easily imagine the structural diversity of new synthesizable materials [3]. In fact, the design and synthesis of metal-organic frameworks (MOFs) is not only because of their fascinating structures and topological novelty, but also because of their existing potential applications as functional materials in gas storage, heterogeneous catalysis, chemical separations, and microelectronics [4-11]. So, the ethylenediaminetetraacetic acid $\left(\mathrm{H}_{4}\right.$ edta $)$ as ligand is a good choice for building a diversified structure; it is not only a plurality of coordination sites but also an inexpensive and relative safe substance, which can remove toxic heavy metals, reduce oxidative stress, and increase waste excretion $[12,13]$. In clinical practice, the chelation therapy with $\mathrm{H}_{4}$ edta can prevent cancer and catalytic reactive oxygen species, such as cardiovascular and arteriosclerotic heart disease [14-16]. So, it is widely used in the pharmaceutical and biological aspects.

As we know, the main group elements do not easily form complexes with organic ligands because of the special properties. But, owing to the presence of a lone pair of electrons, showing stereochemical behavior, the antimony complexes with aminopolycarboxylate ligands have attracted people's interests [17]. Because the inorganic salts of antimony(III) have considerable toxicity, so the new biological activity and medicinal function complexes of the main group element antimony are received more attention $[18,19]$. Besides, some antimony(III) compounds have been used as antiparasitic agents, and exhibit significant functions as biocides, fungicides, antioxidants, and potential therapeutic agents. For example, some antimony compounds are used for treatment of leishmaniasis, various species of the protozoan leishmania virus and cancer [20-25]. 
TABLE 1: Crystal data and structure refinement for the title complex.

\begin{tabular}{|c|c|c|c|}
\hline Empirical formula & $\mathrm{SbC}_{10} \mathrm{H}_{17} \mathrm{~N}_{2} \mathrm{O}_{10}$ & $F(000)$ & 888 \\
\hline Formula weight & 447.01 & Crystal size & $0.46 \mathrm{~mm} \times 0.40 \mathrm{~mm} \times 0.35 \mathrm{~mm}$ \\
\hline Wavelength & $0.71073 \AA$ & Theta range for data collection & $2.89-25.02^{\circ}$ \\
\hline Temperature & $298(2) \mathrm{K}$ & Limiting indices & $-21 \leq h \leq 16,-13 \leq k \leq 13,-7 \leq l \leq 8$ \\
\hline Crystal system & Orthorhombic & Reflections collected/unique & $7102 / 2529[R(\mathrm{int})=0.0461]$ \\
\hline Space group & Pna2(1) & Completeness to theta $=25.02$ & $99.9 \%$ \\
\hline Unit cell dimensions & & Absorption correction & Semiempirical from equivalents \\
\hline$a$ & $18.4823(18) \AA$ & Max. and min. transmission & 0.5547 and 0.4738 \\
\hline$b$ & $10.9408(12) \AA$ & Refinement method & Full-matrix least-squares on $F^{2}$ \\
\hline$c$ & $7.3671(5) \AA$ & Date/restraints/parameters & $2529 / 1 / 208$ \\
\hline$\beta$ & $90.00^{\circ}$ & Goodness-of-fit on $F^{2}$ & 1.040 \\
\hline$V$ & $1489.7(2) \AA^{3}$ & Final $R$ indices $[I>2 \sigma(I)]$ & $R_{1}=0.0332, w R_{2}=0.0811$ \\
\hline$Z$ & 4 & $R$ indices (all data) & $R_{1}=0.0359, w R_{2}=0.0832$ \\
\hline Calculated density & $1.993 \mathrm{~g} \mathrm{~cm}^{-3}$ & Absolute structure parameter & $-0.27(4)$ \\
\hline Absorption coefficient & $1.909 \mathrm{~mm}^{-1}$ & Largest diff. peak and hole & 0.786 and $-0.805 \mathrm{e} \AA^{-3}$ \\
\hline
\end{tabular}

In recent years, owing to the development of aminopolycarboxylic acid complexes of antimony(III) in medicine, the complex of antimony with multicarboxylate ligands has received more and more attention. Herein, we report the syntheses of the title complex [ $\mathrm{Sb}$ (Hedta) $] \cdot 2 \mathrm{H}_{2} \mathrm{O}$. The composition and crystal structure of the complex have been characterized by elemental analysis, single crystal X-ray diffraction, XRD, FTIR, and TG-DSC.

\section{Experimental}

2.1. Materials and General Methods. All the chemicals used in the experiments were analytical reagent as received from commercial sources and without further purification. The ethylenediaminetetraacetic acid and antimonous oxide were purchased from Shanghai Reagent Industry.

The antimony was determined by a Thermo X-II inductively coupled plasma mass spectrometer. The content of carbon, hydrogen, and nitrogen in the complex was measured by a Vario EL CUBE elemental analyzer. The IR spectra were obtained with a Perkin-Elmer Spectrum One-spectrometer in the range of $225-4000 \mathrm{~cm}^{-1}$ using $\mathrm{KBr}$ pellets. The thermogravimetric analysis of the metal complex was performed by an SDT Q600 thermogravimetric analyzer, and the measurement was recorded from 30 to $800^{\circ} \mathrm{C}$ at the heating rate of $10^{\circ} \mathrm{C} \mathrm{min} \mathrm{m}^{-1}$ under air flow of $100 \mathrm{~mL} \mathrm{~min}^{-1}$. The $\mathrm{X}$-ray powder diffraction was performed using a D/max-II X-ray diffractometer, $\mathrm{Cu} \mathrm{K}$ radiation $(\lambda=0.154056 \mathrm{~nm}$, step width: $2 \theta=0.2^{\circ}$, scan speed: $8^{\circ} / \mathrm{min}$ ).

2.2. Synthesis of the Complex $[\mathrm{Sb}(\mathrm{Hedta})] \cdot 2 \mathrm{H}_{2} \mathrm{O}$. The title complex was obtained by aqueous solution synthesis. First, $1.46 \mathrm{~g}$ ( $5 \mathrm{mmol})$ ethylenediaminetetraacetic acid was solubilized in $200 \mathrm{~mL}$ boiling distilled water. Then, $0.875 \mathrm{~g}$ ( $3 \mathrm{mmol})$ antimonous oxide was gradually added to the above solution, stirring and maintaining the temperature at $90^{\circ} \mathrm{C}$. After four hours, when the $\mathrm{pH}$ was about $2-3$, the reaction was stopped. The unreacted antimonous oxide was filtered. The colorless filtrate was slowly concentrated to $100 \mathrm{~mL}$. The concentrated solution was placed at room temperature for about one week, and the colorless flaky crystals of the antimony(III) complex was obtained. The yield was about $82 \%$. Anal. Calcd for the title complex, $\mathrm{SbC}_{10} \mathrm{H}_{17} \mathrm{~N}_{2} \mathrm{O}_{10}(\%)$ : Sb, 27.24; C, 26.87; N, 6.27; $\mathrm{H}, 3.83$. Found (\%): Sb, 27.11; C, 26.68; N, 6.19; H, 3.74.

2.3. X-Ray Diffraction Crystallography. The appropriate crystals were cut from larger crystals and mounted on a Bruker Smart Apex II CCD diffractometer with graphite monochromated Mo $\mathrm{K}_{\alpha}$ radiation $(\lambda=0.71073 \AA)$. The data were collected at 298(2) K. A colorless and transparent crystal with dimensions $0.46 \mathrm{~mm} \times 0.40 \mathrm{~mm} \times 0.35 \mathrm{~mm}$ was mounted on a glass fiber. Diffraction data were collected in $\omega$ mode in the range of $2.89^{\circ}-25.02^{\circ}$. The structure was solved by direct methods SHELXS-97 and refined by full-matrix leastsquares using SHELXL-97 [26, 27]. All nonhydrogen atoms were obtained from the difference Fourier map and fullmatrix least-squares refinements on $F^{2}$ were carried out with anisotropic thermal parameters. Hydrogen atoms of the ligand were generated geometrically. The structure refinement parameters for the title complex are given in Table 1, and the crystallographic data are deposited with the Cambridge Crystallographic Data Centre under deposition number CCDC 953660 .

\section{Results and Discussion}

3.1. X-Ray Crystal Structure Analysis. The single crystal Xray diffraction analysis reveals that the complex [Sb(Hedta)]. $2 \mathrm{H}_{2} \mathrm{O}$ crystallises in the orthorhombic system with space group Pna2(1). Crystallographic data and structure refinement parameters for the title complex are given in Table 1, and the selected bond distances and angles are shown in Table 2. The key fragments of the structures and the atom numbering are shown in Figure 1, and the crystal packing diagram of the complex is shown in Figure 2. The asymmetric unit of the complex consists of one $\mathrm{Hedta}^{3-}$, one trivalent antimony 
TABLE 2: Selected bond lengths $(\AA)$ and angles $\left({ }^{\circ}\right)$ for the title complex.

\begin{tabular}{llcccc}
\hline $\mathrm{Sb}(1)-\mathrm{O}(1)$ & $2.182(4)$ & $\mathrm{O}(7)-\mathrm{C}(9)$ & $1.218(7)$ & $\mathrm{N}(1)-\mathrm{Sb}(1)-\mathrm{N}(2)$ & $75.9(2)$ \\
$\mathrm{Sb}(1)-\mathrm{O}(5)$ & $2.199(4)$ & $\mathrm{O}(8)-\mathrm{C}(9)$ & $1.299(7)$ & $\mathrm{C}(4)-\mathrm{N}(1)-\mathrm{Sb}(1)$ & $\mathrm{C}(6)-\mathrm{N}(1)-\mathrm{Sb}(1)$ \\
$\mathrm{Sb}(1)-\mathrm{O}(3)$ & $2.243(4)$ & $\mathrm{O}(1)-\mathrm{Sb}(1)-\mathrm{O}(5)$ & $142.8(2)$ & $\mathrm{C}(1)-\mathrm{N}(1)-\mathrm{Sb}(1)$ & $107.5(3)$ \\
$\mathrm{Sb}(1)-\mathrm{N}(1)$ & $2.336(5)$ & $\mathrm{O}(1)-\mathrm{Sb}(1)-\mathrm{O}(3)$ & $85.36(16)$ & $\mathrm{C}(8)-\mathrm{N}(2)-\mathrm{Sb}(1)$ & $108.6(4)$ \\
$\mathrm{Sb}(1)-\mathrm{N}(2)$ & $2.402(5)$ & $\mathrm{O}(5)-\mathrm{Sb}(1)-\mathrm{O}(3)$ & $74.09(16)$ & $\mathrm{C}(2)-\mathrm{N}(2)-\mathrm{Sb}(1)$ & $104.8(3)$ \\
$\mathrm{O}(1)-\mathrm{C}(3)$ & $1.307(8)$ & $\mathrm{O}(1)-\mathrm{Sb}(1)-\mathrm{N}(1)$ & $75.60(18)$ & $\mathrm{C}(10)-\mathrm{N}(2)-\mathrm{Sb}(1)$ & $108.5(3)$ \\
$\mathrm{O}(2)-\mathrm{C}(3)$ & $1.222(7)$ & $\mathrm{O}(5)-\mathrm{Sb}(1)-\mathrm{N}(1)$ & $71.03(17)$ & $\mathrm{C}(3)-\mathrm{O}(1)-\mathrm{Sb}(1)$ & $114.9(4)$ \\
$\mathrm{O}(3)-\mathrm{C}(5)$ & $1.273(7)$ & $\mathrm{O}(3)-\mathrm{Sb}(1)-\mathrm{N}(1)$ & $78.88(16)$ & $\mathrm{C}(7)-\mathrm{O}(5)-\mathrm{Sb}(1)$ & $120.0(4)$ \\
$\mathrm{O}(4)-\mathrm{C}(5)$ & $1.229(7)$ & $\mathrm{O}(1)-\mathrm{Sb}(1)-\mathrm{N}(2)$ & $73.26(17)$ & $\mathrm{C}(5)-\mathrm{O}(3)-\mathrm{Sb}(1)$ \\
$\mathrm{O}(5)-\mathrm{C}(7)$ & $1.286(7)$ & $\mathrm{O}(5)-\mathrm{Sb}(1)-\mathrm{N}(2)$ & $144.17(16)$ & \\
$\mathrm{O}(6)-\mathrm{C}(7)$ & $1.238(7)$ & $\mathrm{O}(3)-\mathrm{Sb}(1)-\mathrm{N}(2)$ & & $120.1(4)$ \\
\hline
\end{tabular}

TABLE 3: Hydrogen bond lengths $(\AA)$ and bond angles $\left({ }^{\circ}\right)$ for the title complex.

\begin{tabular}{lccccc}
\hline $\mathrm{D}-\mathrm{H}$ & $d(\mathrm{D}-\mathrm{H})$ & $d(\mathrm{H} \cdots \mathrm{A})$ & $d(\mathrm{D} \cdots \mathrm{A})$ & LDHA & A symmetry operation \\
\hline O8-H8 & 0.820 & 1.742 & 2.556 & 171.90 & O9 \\
O9-H9C & 0.850 & 1.854 & 2.702 & 175.29 & $\mathrm{O} 4\left[-x+\frac{1}{2}, y+\frac{1}{2}, z+\frac{1}{2}\right]$ \\
O9-H9D & 0.850 & 1.935 & 2.783 & 175.28 & O6 $\left[-x+1,-y+1, z+\frac{1}{2}\right]$ \\
O10-H10E & 0.850 & 2.110 & 2.950 & 169.24 & O9 \\
O10-H10F & 0.850 & 2.091 & 2.930 & 169.18 & O2 $\left[-x+\frac{1}{2}, y-\frac{1}{2}, z+\frac{1}{2}\right]$ \\
\hline
\end{tabular}

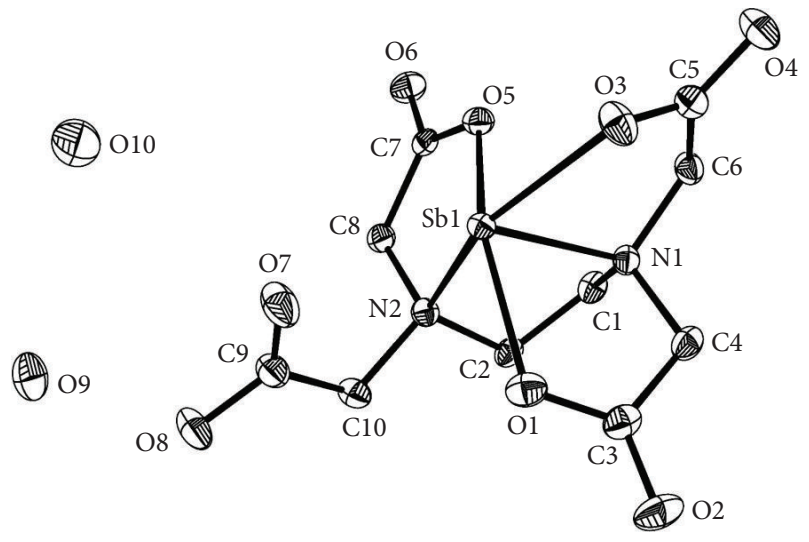

Figure 1: The molecular structure of the title complex.

ion, and two crystalline water molecules. $\mathrm{Sb}$ (III) ion for plane forms a distorted trigonal bipyramidal configuration. The $\mathrm{Sb}$ (III) ion is five-coordinated by three carboxyl oxygen atoms (O1, O3, and $\mathrm{O} 5)$ and two nitrogen atoms (N1 and N2) from the same $\mathrm{Hedta}^{3-}$ ligand. Therefore, a carboxyl group (O7 and O8) and all water molecules in the title complex are not coordinated. The bond lengths of Sb1-O1, Sb1-O3, and Sb1-O5 are in the range of 2.182-2.243 $\AA$, and it belongs to the typical distance of the aminopolycarboxylate complexes of antimony(III) [28]. But, with respect to the bond lengths of $\mathrm{C}-\mathrm{O}$, there are two types of carboxyl groups in the complex. The C5(7)-O3(5) is longer than C5(7)-O4(6), about $0.04 \AA$, like the usual ionized carboxyl group. But, the $\mathrm{C} 3(9)-\mathrm{O} 1(8)$ is longer than $\mathrm{C} 3(9)-\mathrm{O} 2(7)$, about $0.08 \AA$, which is comparable with the value of a free carboxylic acid, and this type of coordination seems to cause the especially strong acidity of Sb-(Hedta). The bond angles of N1-Sb1-O3, N1-Sb1-O5, N1-Sb1-N2, and N1-Sb1-O1 are almost similar; if the Sb1$\mathrm{N} 1$ is perpendicular to the equator plane, they look like an inverted umbrella, and the $\mathrm{Sb}-\mathrm{N}$ bond lengths are 2.336(5) $\AA$ and 2.402(5) $\AA$, and the $\mathrm{Sb}-\mathrm{O}$ band lengths are $\mathrm{Sb1}-\mathrm{O} 1=$ 2.182(4) $\AA$, Sb1-O3 = 2.243(4) $\AA$, and Sb1-O5 = 2.199(4) $\AA$, respectively.

In Tables 2 and 3, there are three types of hydrogen bonds in the crystal of the $\mathrm{Sb}$ (III) complex, and they include the weak hydrogen bonds between the crystalline water molecules (O10-H10E ... O9, $2.950 \AA$ ), the crystalline water and the oxygen atoms of the carbonyl groups (O9H9C...O 4, 2.702 $\AA$; O9-H9D ... O6, 2.783 $\AA$, and O10$\mathrm{H} 10 \mathrm{~F} \cdot \mathrm{OO} 2,2.930 \AA$ ), and the strong hydrogen bonds between the crystalline water and the oxygen atoms of the hydroxyl groups (O8-H8 ‥ O9, $2.556 \AA)$. In Figure 3, because there are a lot of crystal water molecules in the complex, the interstitial water molecules and the carboxyl oxygen atoms will form hydrogen bonds, which make the structure more stable.

3.2. X-Ray Powder Diffraction. The X-ray powder diffraction data of $[\mathrm{Sb}(\mathrm{Hedta})] \cdot 2 \mathrm{H}_{2} \mathrm{O}$ was collected in the diffraction angle range of $3^{\circ}-80^{\circ}$. The XRD pattern of the complex is shown in Figure 4(a). The main diffraction peaks appear at $2 \theta=9.56^{\circ}, 15.30^{\circ}$, and $16.85^{\circ}$ for the title complex. The index calculation of the XRD data bases on the computer program of least squares method [29] and the calculated results are 


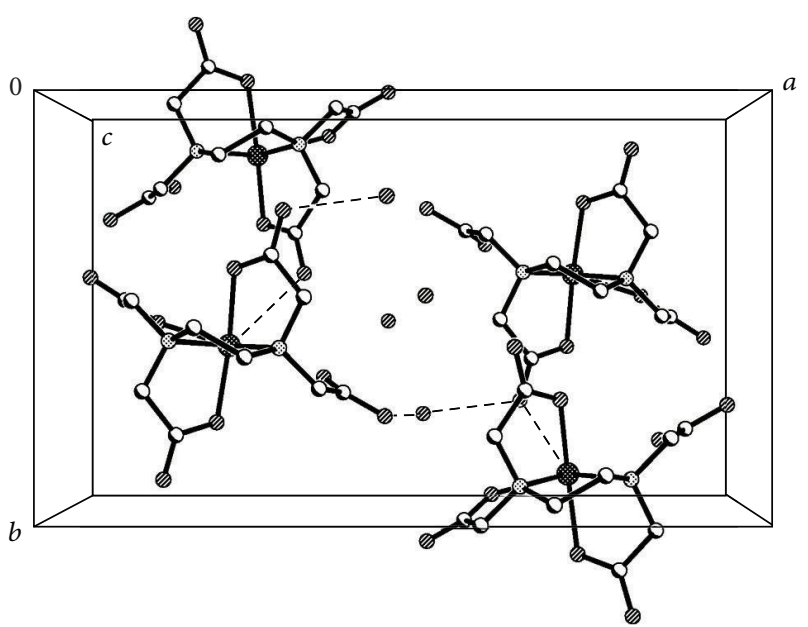

FIGURE 2: Crystal packing diagram of the title complex.

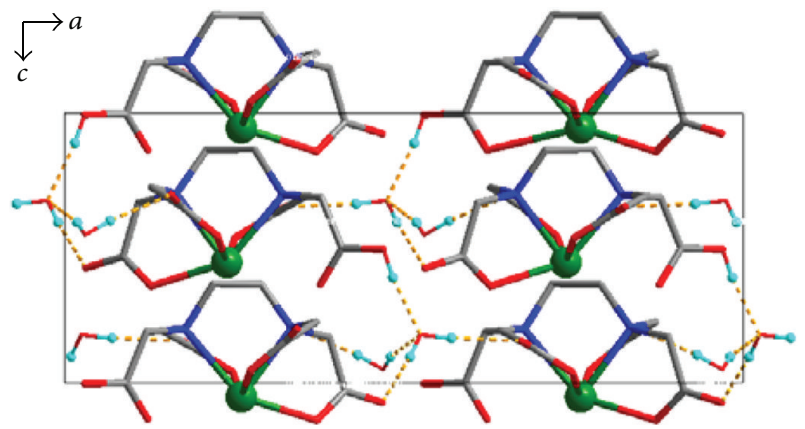

Figure 3: Packing diagram of the title complex showing $\mathrm{H}$ bonding along the $b$ axis.

shown in Table 4 . Table 4 shows that the calculated spacing $d_{h k l}$ is consistent with the experimental ones, and the largest relative deviation between the experimental and calculated spacing $d_{h k l}$ is less than $0.3 \%$. This indicates that the resultant is a single phase compound [17]. The crystal structure of the complex belongs to an orthorhombic system with the lattice parameters: $a=18.479 \AA, b=10.957 \AA$, and $c=$ $7.343 \AA$, respectively. The results of indexes to the XRD data for the complex are consistent with the results of single crystal. The experimental pattern exhibiting some peaks is slightly broadened in comparison with the simulated pattern in Figure 4(b), which may be due to the preferred orientation of the powder samples. The experimental XRD pattern agrees well with the simulated pattern generated on the basis of the single crystal analyses for the title complex.

3.3. FT-IR Spectra. The FT-IR spectra of the title complex are shown in Figure 5. The infrared spectra of the complex show that wide absorption bands in the region $3400-3600 \mathrm{~cm}^{-1}$ can be assigned to the $\mathrm{O}-\mathrm{H}$ stretching vibration of the water molecules. The peaks observed from 3017 to $2927 \mathrm{~cm}^{-1}$ are in good agreement with the $\mathrm{C}-\mathrm{H}$ vibrations. If the band at $1700-1750 \mathrm{~cm}^{-1}$ shows the existence of a free carboxyl group, while at about $1650 \mathrm{~cm}^{-1}$, suggests that carboxyl groups are

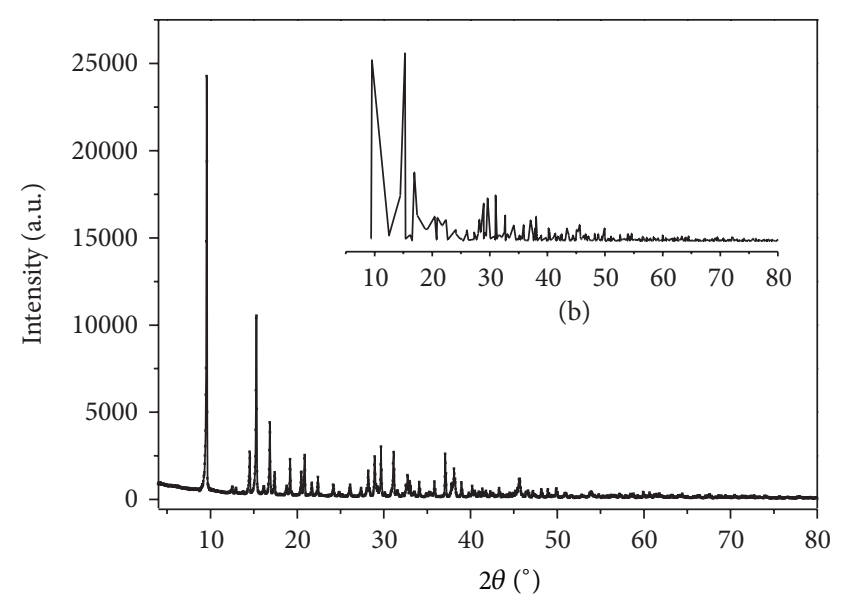

(a)

FIGURE 4: XRD patterns for title complex generated from the experimental data (a) and simulated from the single crystal X-ray data (b).

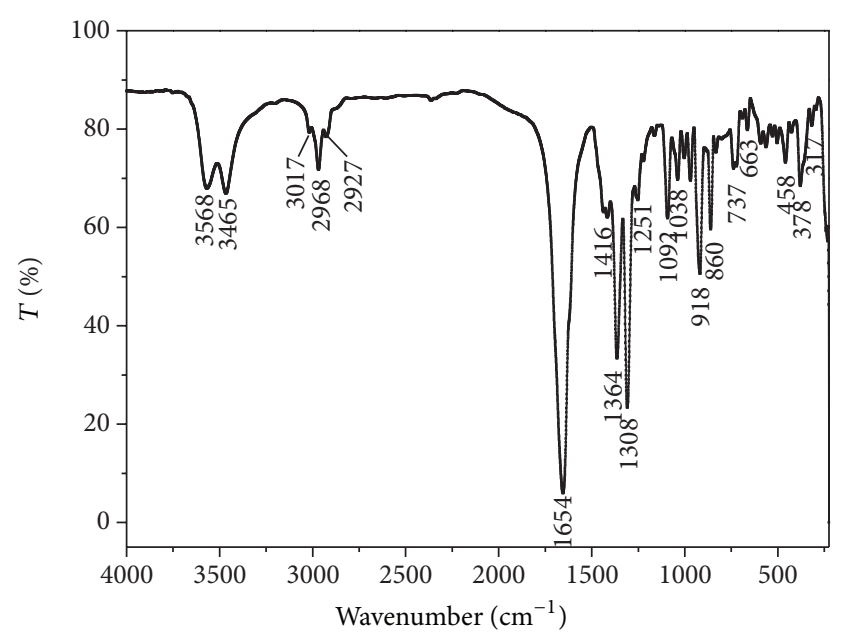

FIGURE 5: FT-IR spectra of the title complex.

coordinated. In which, the $v_{\mathrm{as}}(\mathrm{COO})$ band of the complex $[\mathrm{Sb}($ Hedta $)] \cdot 2 \mathrm{H}_{2} \mathrm{O}$ appears at $1654 \mathrm{~cm}^{-1}$, both $1364 \mathrm{~cm}^{-1}$ and $1308 \mathrm{~cm}^{-1}$ are the $\nu_{s}(\mathrm{COO})$ bands The difference value of $290 \mathrm{~cm}^{-1}$ and $346 \mathrm{~cm}^{-1}$ between the asymmetric and symmetric stretching vibration of the carboxylate group is in line with a monodentate type of coordination [29]. In addition, $1092 \mathrm{~cm}^{-1}$ is the specific absorption peak about the $\mathrm{C}-\mathrm{N}$ vibrations. Compared with the $\mathrm{Na}_{2} \mathrm{H}_{2}$ edta ligand, the $\mathrm{C}-\mathrm{N}$ at $1137 \mathrm{~cm}^{-1}$ shifts towards lower frequencies, and it confirms that the nitrogen atoms of the ligand are coordinated to the $\mathrm{Sb}$ (III) ion. In the far-infrared region, the absorption peak found in the $378 \mathrm{~cm}^{-1}$ region is assigned to the $v(\mathrm{Sb}-\mathrm{N})$ vibration and in the $317 \mathrm{~cm}^{-1}$ region is assigned to the $\nu(\mathrm{Sb}-$ O) stretching vibration.

3.4. Thermal Analysis. The thermal decomposition process of complexes can help us understand the coordination structure 
TABLE 4: Experimental data and calculated results for powder X-ray diffraction pattern of the complex [ $\mathrm{Sb}(\mathrm{Hedta})] \cdot 2 \mathrm{H}_{2} \mathrm{O}$ (orthorhombic system: $a=18.479 \AA, b=10.957 \AA$, and $c=7.343 \AA$ ).

\begin{tabular}{|c|c|c|c|c|c|c|c|}
\hline No. & $2 \theta\left(^{\circ}\right)$ & $h$ & $k$ & $l$ & $d_{\exp }(\AA)$ & $d_{\text {cal }}(\AA)$ & $I / I_{0}$ \\
\hline 1 & 9.56 & 2 & 0 & 0 & 9.242 & 9.240 & 100.0 \\
\hline 2 & 12.52 & 2 & 1 & 0 & 7.064 & 7.063 & 1.5 \\
\hline 3 & 12.96 & 1 & 0 & 1 & 6.827 & 6.824 & 1.2 \\
\hline 4 & 14.51 & 0 & 1 & 1 & 6.100 & 6.100 & 9.5 \\
\hline 5 & 15.30 & 1 & 1 & 1 & 5.788 & 5.792 & 42.6 \\
\hline 6 & 16.17 & 0 & 2 & 0 & 5.477 & 5.478 & 1.6 \\
\hline 7 & 16.85 & 1 & 2 & 0 & 5.256 & 5.253 & 17.2 \\
\hline 8 & 17.41 & 2 & 1 & 1 & 5.090 & 5.091 & 5.2 \\
\hline 9 & 18.11 & 2 & 2 & 0 & 4.713 & 4.712 & 2.1 \\
\hline 10 & 19.19 & 4 & 0 & 0 & 4.621 & 4.620 & 8.5 \\
\hline 11 & 20.48 & 3 & 1 & 1 & 4.332 & 4.334 & 5.5 \\
\hline 12 & 20.85 & 4 & 1 & 0 & 4.257 & 4.257 & 9.7 \\
\hline 13 & 21.69 & 3 & 2 & 0 & 4.094 & 4.094 & 3.0 \\
\hline 14 & 22.40 & 2 & 2 & 1 & 3.966 & 3.966 & 4.5 \\
\hline 15 & 24.15 & 4 & 1 & 1 & 3.682 & 3.683 & 2.7 \\
\hline 16 & 24.86 & 1 & 3 & 0 & 3.579 & 3.583 & 0.9 \\
\hline 17 & 26.10 & 2 & 0 & 2 & 3.411 & 3.412 & 2.8 \\
\hline 18 & 27.37 & 2 & 1 & 2 & 3.256 & 3.258 & 1.8 \\
\hline 19 & 28.21 & 3 & 0 & 2 & 3.160 & 3.154 & 5.9 \\
\hline 20 & 28.95 & 6 & 0 & 0 & 3.081 & 3.080 & 9.4 \\
\hline 21 & 29.69 & 1 & 2 & 2 & 3.007 & 3.009 & 11.8 \\
\hline 22 & 31.12 & 4 & 0 & 2 & 2.871 & 2.874 & 10.6 \\
\hline 23 & 31.61 & 5 & 2 & 1 & 2.828 & 2.828 & 1.3 \\
\hline 24 & 32.73 & 3 & 2 & 2 & 2.733 & 2.733 & 5.0 \\
\hline 25 & 33.00 & 1 & 4 & 0 & 2.712 & 2.710 & 3.6 \\
\hline 26 & 33.54 & 4 & 3 & 1 & 2.670 & 2.669 & 1.1 \\
\hline 27 & 34.10 & 2 & 4 & 0 & 2.627 & 2.626 & 3.4 \\
\hline 28 & 35.24 & 1 & 4 & 1 & 2.544 & 2.542 & 1.1 \\
\hline 29 & 35.84 & 3 & 4 & 0 & 2.503 & 2.503 & 3.5 \\
\hline 30 & 37.07 & 1 & 0 & 3 & 2.423 & 2.426 & 10.2 \\
\hline 31 & 37.80 & 7 & 2 & 0 & 2.378 & 2.378 & 3.0 \\
\hline 32 & 38.11 & 2 & 0 & 3 & 2.360 & 2.366 & 6.7 \\
\hline 33 & 38.95 & 2 & 1 & 3 & 2.311 & 2.313 & 3.4 \\
\hline 34 & 39.81 & 4 & 3 & 2 & 2.262 & 2.259 & 0.8 \\
\hline 35 & 40.18 & 4 & 4 & 1 & 2.242 & 2.244 & 2.5 \\
\hline 36 & 40.50 & 1 & 2 & 3 & 2.225 & 2.219 & 1.2 \\
\hline 37 & 40.95 & 0 & 4 & 2 & 2.202 & 2.196 & 0.9 \\
\hline 38 & 41.39 & 2 & 2 & 3 & 2.178 & 2.172 & 1.7 \\
\hline 39 & 41.77 & 4 & 0 & 3 & 2.161 & 2.163 & 1.2 \\
\hline 40 & 42.28 & 7 & 0 & 2 & 2.137 & 2.143 & 1.1 \\
\hline 41 & 43.31 & 1 & 5 & 1 & 2.087 & 2.086 & 1.9 \\
\hline 42 & 45.19 & 4 & 2 & 3 & 2.006 & 2.012 & 1.3 \\
\hline 43 & 45.69 & 2 & 3 & 3 & 1.984 & 1.986 & 4.1 \\
\hline 44 & 46.62 & 8 & 3 & 0 & 1.947 & 1.952 & 1.3 \\
\hline 45 & 47.18 & 3 & 3 & 3 & 1.926 & 1.931 & 1.2 \\
\hline 46 & 48.17 & 5 & 4 & 2 & 1.888 & 1.888 & 1.8 \\
\hline 47 & 48.93 & 4 & 3 & 3 & 1.860 & 1.861 & 1.8 \\
\hline
\end{tabular}

TABLE 4: Continued.

\begin{tabular}{lccccccc}
\hline No. & $2 \theta\left(^{\circ}\right)$ & $h$ & $k$ & $l$ & $d_{\exp }(\AA)$ & $d_{\text {cal }}(\AA)$ & $I / I_{0}$ \\
\hline 48 & 49.89 & 0 & 4 & 3 & 1.826 & 1.825 & 1.9 \\
49 & 50.90 & 2 & 4 & 3 & 1.792 & 1.791 & 1.0 \\
50 & 53.92 & 4 & 4 & 3 & 1.698 & 1.697 & 1.3 \\
51 & 58.45 & 3 & 6 & 2 & 1.578 & 1.580 & 0.8 \\
52 & 58.77 & 0 & 7 & 0 & 1.569 & 1.565 & 0.8 \\
53 & 59.94 & 2 & 7 & 0 & 1.542 & 1.543 & 1.2 \\
54 & 60.66 & 0 & 4 & 4 & 1.525 & 1.525 & 1.1 \\
55 & 61.79 & 5 & 3 & 4 & 1.500 & 1.499 & 0.9 \\
56 & 64.46 & 2 & 1 & 5 & 1.442 & 1.438 & 0.9 \\
57 & 67.57 & 2 & 5 & 4 & 1.388 & 1.391 & 0.9 \\
\hline
\end{tabular}

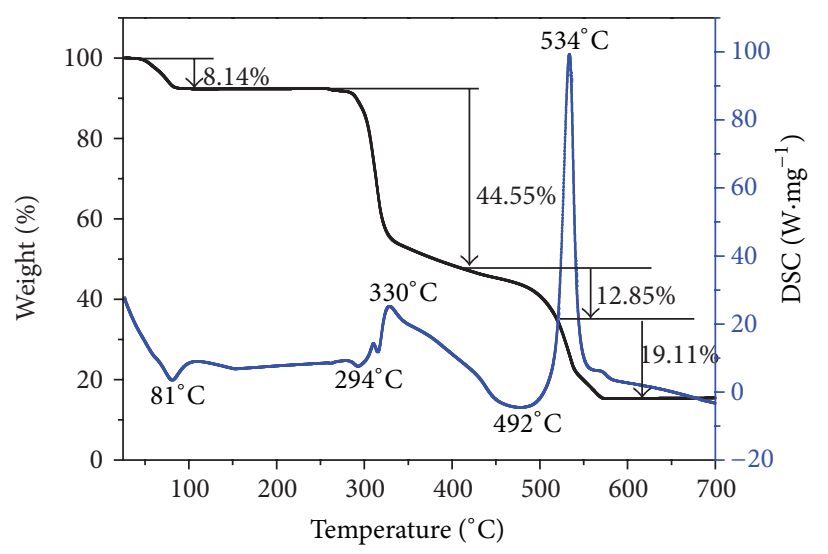

FIgURE 6: TG-DSC curves of the title complex.

of the complexes [30]. The TG-DSC curves of the title complex are given in Figure 6, and the possible pyrolysis reaction and the experimental and calculated percentage mass losses in the thermal decomposition process of the complex are summarized in Table 5. The first mass loss of the complex [ $\mathrm{Sb}$ (Hedta)] $2 \mathrm{H}_{2} \mathrm{O}$ occurs about $81^{\circ} \mathrm{C}$ in DSC curve, corresponding to the release of two molecules in crystalline water. This is consistent with the single crystal structure. The experimental percentage mass loss $(8.14 \%)$ is close to the calculated one (8.06\%). Then, a small endothermic peak in DSC curve appears at $294^{\circ} \mathrm{C}$. Because there is not any corresponding mass loss of the sample in the TG curve, it can be attributable to structure rearrangement or phase transformation in the solid complex. Thereafter, the exothermic peak at $330^{\circ} \mathrm{C}$ corresponds to oxidation and decomposition of the ligand, and the experimental mass loss (44.55\%) is close to the calculated one (44.57\%). This step decomposition product is $\mathrm{Sb}_{2}\left(\mathrm{CO}_{3}\right)_{3}$. Then, $\mathrm{Sb}_{2}\left(\mathrm{CO}_{3}\right)_{3}$ is decomposed into $\mathrm{Sb}_{2} \mathrm{O}_{4}$ (Scheme 1), and the experimental and theoretical mass losses are $12.85 \%$ and $12.98 \%$, respectively. This is why there is an appreciable endothermic peak at $492^{\circ} \mathrm{C}$ in DSC curve. However, some of the compounds of antimony may be volatile at high temperature. The final step of the exothermic peak appears at $534^{\circ} \mathrm{C}$ in DSC curve. The $\mathrm{Sb}-\mathrm{O}$ single bond is ruptured, and then half of the antimony compound may 
TABLE 5: Thermal decomposition data of the title complex.

\begin{tabular}{|c|c|c|c|}
\hline \multirow{2}{*}{ Reaction } & \multirow{2}{*}{$\operatorname{DSC}\left({ }^{\circ} \mathrm{C}\right)$} & \multicolumn{2}{|c|}{ Mass loss (\%) } \\
\hline & & $W_{\exp }$ & $W_{\text {theor }}$ \\
\hline \multicolumn{4}{|l|}{$[\mathrm{Sb}(\mathrm{Hedta})] \cdot 2 \mathrm{H}_{2} \mathrm{O}$} \\
\hline$\downarrow-2 \mathrm{H}_{2} \mathrm{O}$ & 81 (endo.) & 8.14 & 8.06 \\
\hline \multicolumn{4}{|l|}{$[\mathrm{Sb}($ Hedta $)]$} \\
\hline$\downarrow$ structural rearrangement & 294 (endo.) & & \\
\hline \multicolumn{4}{|l|}{$[\mathrm{Sb}($ Hedta $)]$} \\
\hline$\downarrow-\mathrm{C}_{8.5} \mathrm{H}_{13} \mathrm{~N}_{2} \mathrm{O}_{3.5}$ & 330 (exo.) & 44.55 & 44.57 \\
\hline \multicolumn{4}{|l|}{$1 / 2 \mathrm{Sb}_{2}\left(\mathrm{CO}_{3}\right)_{3}$} \\
\hline$\downarrow-\mathrm{C}_{3} \mathrm{O}_{5}$ & 492 (ехо.) & 12.85 & 12.98 \\
\hline \multicolumn{4}{|l|}{$1 / 2 \mathrm{Sb}_{2} \mathrm{O}_{4}$} \\
\hline$\downarrow-\mathrm{Sb}_{0.5} \mathrm{O}_{1.25}$ & 534 (endo.) & 19.11 & 18.09 \\
\hline $1 / 4 \mathrm{Sb}_{2} \mathrm{O}_{3}$ & & $15.35^{\mathrm{a}}$ & $16.30^{\mathrm{b}}$ \\
\hline
\end{tabular}



SCHEME 1: Structure of the $\mathrm{Sb}_{2} \mathrm{O}_{4}$.

be oxidized and volatilized. The final residue is antimonous oxide, and the experimental result (15.35\%) is in agreement with the result of theoretical calculation (16.30\%).

\section{Conclusion}

The complex $[\mathrm{Sb}$ (Hedta) $] \cdot 2 \mathrm{H}_{2} \mathrm{O}$ was synthesized with the reaction of ethylenediaminetetraacetic acid and antimonous oxide as the reactants. The composition and structure of the complex were characterized by EA, singlerystal X-ray diffraction, XRD, FTIR, and TG-DSC. The crystal structure of the complex belongs to orthorhombic system, space group Pna2(1), with cell parameters of $a=18.4823(18) \AA, b=$ 10.9408(12) $\AA, c=7.3671(5) \AA, Z=4$, and $D_{c}=$ $1.993 \mathrm{~g} \mathrm{~cm}^{-3}$. $\mathrm{Sb}$ (III) ion is five-coordinated by two amido $\mathrm{N}$ atoms and three carboxyl $\mathrm{O}$ atoms from a single $\mathrm{Hedta}^{3-}$ ligand, forming a distorted trigonal bipyramid geometry.

\section{Extra Material}

Crystallographic data for the title complex [Sb(Hedta) $] \cdot 2 \mathrm{H}_{2} \mathrm{O}$ has been deposited with the Cambridge Crystallographic Data Centre. The deposition number is CCDC-953660. The data can be obtained free of charge on application to the Director, CCDC, 12 Union Road, Cambridge, CB2 1EZ, UK, fax: +44 1223366 033, e-mail: deposit@ccdc.ac.uk, or on the web: www: http://www.ccdc.cam.ac.uk, or from the authors up on request.

\section{Conflict of Interests}

The authors declare that there is no conflict of interests regarding the publication of this paper.

\section{Acknowledgments}

The authors gratefully acknowledge the financial support from the National Natural Science Foundation of China (no. 21201142) and the Scientific Research Funds of Sichuan Provincial Education Department of China (no. 10ZA016). The authors are very grateful to State Key Laboratory Cultivation Base for Nonmetal Composite and Functional Materials and Engineering Research Center of Biomass Materials of Education Ministry for the testing.

\section{References}

[1] J. A. Lessa, D. C. Reis, I. C. Mendes et al., "Antimony(III) complexes with pyridine-derived thiosemicarbazones: structural studies and investigation on the antitrypanosomal activity," Polyhedron, vol. 30, no. 2, pp. 372-380, 2011.

[2] D. C. Reis, M. C. X. Pinto, E. M. Souza-Fagundes, S. M. S. V. Wardell, J. L. Wardell, and H. Beraldo, "Antimony(III) complexes with 2-benzoylpyridine-derived thiosemicarbazones: cytotoxicity against human leukemia cell lines," European Journal of Medicinal Chemistry, vol. 45, no. 9, pp. 3904-3910, 2010.

[3] A. Y. Robin and K. M. Fromm, "Coordination polymer networks with $\mathrm{O}$ - and $\mathrm{N}$-donors: what they are, why and how they are made," Coordination Chemistry Reviews, vol. 250, no. 15-16, pp. 2127-2157, 2006.

[4] J. Cui, Y. Li, Z. Guo, and H. Zheng, "A porous metal-organic framework based on $\mathrm{Zn}_{6} \mathrm{O}_{2}$ clusters: chemical stability, gas adsorption properties and solvatochromic behavior," Chemical Communications, vol. 49, no. 6, pp. 555-557, 2013.

[5] G. H. Cui, C. H. He, C. H. Jiao, J. C. Geng, and V. A. Blatov, “Two metal-organic frameworks with unique high-connected binodal network topologies: synthesis, structures, and catalytic properties," Chemical Engineering Communications, vol. 14, no. 12, pp. 4210-4216, 2012. 
[6] X. L. Zhao, D. Sun, S. Yuan et al., "Comparison of the effect of functional groups on gas-uptake capacities by fixing the volumes of cages $\mathrm{A}$ and $\mathrm{B}$ and modifying the inner wall of cage C in rht-type MOFs," Inorganic Chemistry, vol. 51, no. 19, pp. 10350-10355, 2012.

[7] S. R. Kim, K. W. Dawson, B. S. Gelfand, J. M. Taylor, and G. K. Shimizu, "Enhancing proton conduction in a metal-organic framework by isomorphous ligand replacement," Journal of the American Chemical Society, vol. 135, no. 3, pp. 963-966, 2013.

[8] X. T. Zhang, D. Sun, B. Li, L. M. Fan, B. Li, and P. H. Wei, "Unusual high thermal stablility of a $2 \mathrm{D} \rightarrow 3 \mathrm{D}$ polycatenated $\mathrm{Fe}(\mathrm{II})$ metal-organic framework showing guest-dependent spin-crossover behavior and high spin-transition temperature," Crystal Growth \& Design, vol. 12, no. 8, pp. 3845-3848, 2012.

[9] J.-P. Zhang, Y.-B. Zhang, J.-B. Lin, and X.-M. Chen, "Metal azolate frameworks: from crystal engineering to functional materials," Chemical Reviews, vol. 112, no. 2, pp. 1001-1033, 2012.

[10] D. Sun, G.-G. Luo, N. Zhang, R.-B. Huang, and L.-S. Zheng, "Simultaneous self-assembly of a cage-like silver(i) complex encapsulating an Ag6 neutral cluster core and carbon dioxide fixation," Chemical Communications, vol. 47, no. 5, pp. 14611463, 2011.

[11] D. Banerjee and J. B. Parise, "Recent advances in s-block metal carboxylate networks," Crystal Growth and Design, vol. 11, no. 10, pp. 4704-4720, 2011.

[12] K. C. Atwood IV, E. Woockner, R. S. Baratz, and W. I. Sampson, "Why the NIH Trial to Assess Chelation Therapy (TACT) should be abandoned," MedGenMed Medscape General Medicine, vol. 10, no. 5, article 115, 2008.

[13] W. Blumer and E. M. Cranton, "Ninety percent reduction in cancer mortality after chelation therapy with EDTA," Journal of Advancement in Medicine, vol. 2, no. 1-2, pp. 183-188, 1989.

[14] A. M. van Rij, C. Solomon, S. G. K. Packer, and W. G. Hopkins, "Chelation therapy for intermittent claudication: a doubleblind, randomized, controlled trial," Circulation, vol. 90, no. 3 , pp. 1194-1199, 1994.

[15] E. Ernst, "Chelation therapy for coronary heart disease: an overview of all clinical investigations," American Heart Journal, vol. 140, no. 1, pp. 139-141, 2000.

[16] M. L. Knudtson, D. G. Wyse, P. D. Galbraith et al., "Chelation therapy for ischemic heart disease: a randomized controlled trial," Journal of the American Medical Association, vol. 287, no. 4, pp. 481-486, 2002.

[17] G. Q. Zhong and Y. C. Guo, "Studies on synthesis and indexes of X-ray powder diffraction data of hydrogen ethylenediamine terraacetato-antimony(III) monohydrate," Journal of Changde Teachers University, vol. 14, no. 3, pp. 39-42, 2002.

[18] A.-K. Leuz, H. Mönch, and C. A. Johnson, "Sorption of Sb(III) and $\mathrm{Sb}(\mathrm{V})$ to goethite: influence on $\mathrm{Sb}(\mathrm{III})$ oxidation and mobilization," Environmental Science and Technology, vol. 40, no. 23, pp. 7277-7282, 2006.

[19] M. Filella, N. Belzile, and Y.-W. Chen, "Antimony in the environment: a review focused on natural waters II. Relevant solution chemistry," Earth-Science Reviews, vol. 59, no. 1-4, pp. 265-285, 2002.

[20] S. Rais, A. Perianin, M. Lenoir et al., "Sodium stibogluconate (Pentostam) potentiates oxidant production in murine visceral leishmaniasis and in human blood," Antimicrobial Agents and Chemotherapy, vol. 44, no. 9, pp. 2406-2410, 2000.

[21] R. C. Palenik, K. A. Abboud, and G. J. Palenik, "Bond valence sums and structural studies of antimony complexes containing
Sb bonded only to O ligands," Inorganica Chimica Acta, vol. 358, no. 4, pp. 1034-1040, 2005.

[22] G. Cantos, C. L. Barbieri, M. Iacomini, P. A. J. Gorin, and L. R. Travassos, "Synthesis of antimony complexes of yeast mannan and mannan derivatives and their effect on Leishmania-infected macrophages," Biochemical Journal, vol. 289, no. 1, pp. 155-160, 1993.

[23] J. Shen, B. Jin, Q. Jiang, G. Zhong, Y. Hu, and J. Huo, "Synthesis, characterization, and magnetic properties of heterometallic trinuclear complex with Sb(III) and Ho(III)," Inorganica Chimica Acta, vol. 385, pp. 158-163, 2012.

[24] P. Sharma, D. Perez, A. Cabrera, N. Rosas, and J. L. Arias, "Perspectives of antimony compounds in oncology," Acta Pharmacologica Sinica, vol. 29, no. 8, pp. 881-890, 2008.

[25] S. K. Hadjikakou, C. D. Antoniadis, N. Hadjiliadis et al., "Synthesis and characterization of new water stable antimony(III) complex with pyrimidine-2-thione and in vitro biological study," Inorganica Chimica Acta, vol. 358, no. 10, pp. 2861-2866, 2005.

[26] G. M. Sheldrick, SHELXS 97, Program for the Solution of Crystal Structure, University of Göttingen, 1997.

[27] G. M. Sheldrick, SHELXS 97, Program for the Refinement of Crystal Structure, University of Göttingen, 1997.

[28] M. Shimoi, Y. Orita, T. Uehiro et al., "The Structure of (hydrogen ethylenediaminetetraacetato) antimony(III) dihydrate $\mathrm{Sb}\left(\mathrm{C}_{10} \mathrm{H}_{13} \mathrm{~N}_{2} \mathrm{O}_{8}\right) \cdot 2 \mathrm{H}_{2} \mathrm{O}$," Bulletin of the Chemical Society of Japan, vol. 53, no. 11, pp. 3189-3194, 1980.

[29] G.-Q. Zhong, Y.-C. Guo, Y.-R. Chen, X.-S. Zang, and S.-R. Luan, "Synthesis and crystal structure of the complex of thioglycollic acid and trivalent antimony ion," Acta Chimica Sinica, vol. 59, no. 10, pp. 1599-1603, 2001.

[30] G. Q. Zhong, J. Shen, Q. Y. Jiang, Y. Q. Jia, M. J. Chen, and Z. P. Zhang, "Synthesis, characterization and thermal decompositionof $\mathrm{Sb}^{\mathrm{III}}-\mathrm{M}-\mathrm{Sb}^{\mathrm{III}}$ type trinuclear complexes of ethylenediamine-N, N, N', $N^{\prime}$-tetraacetate (M:Co(II), La(III), $\mathrm{Nd}(\mathrm{III}), \mathrm{Dy}(\mathrm{III}))$," Journal of Thermal Analysis and Calorimetry, vol. 92, no. 2, pp. 607-616, 2008. 

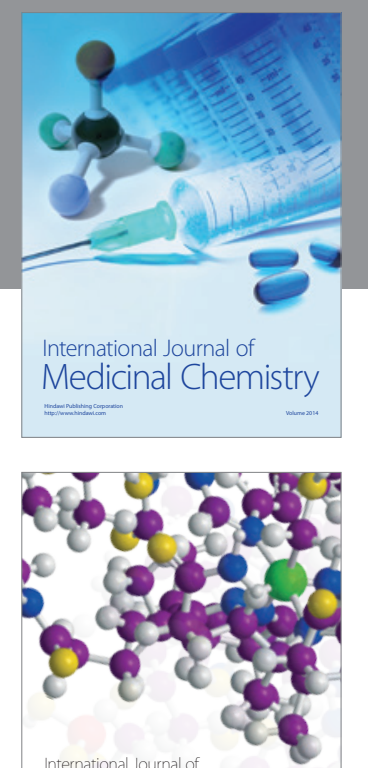

\section{Carbohydrate} Chemistry

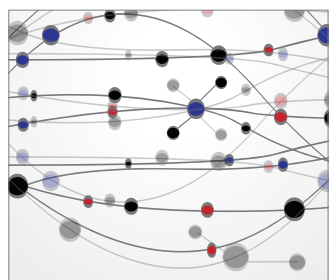

The Scientific World Journal

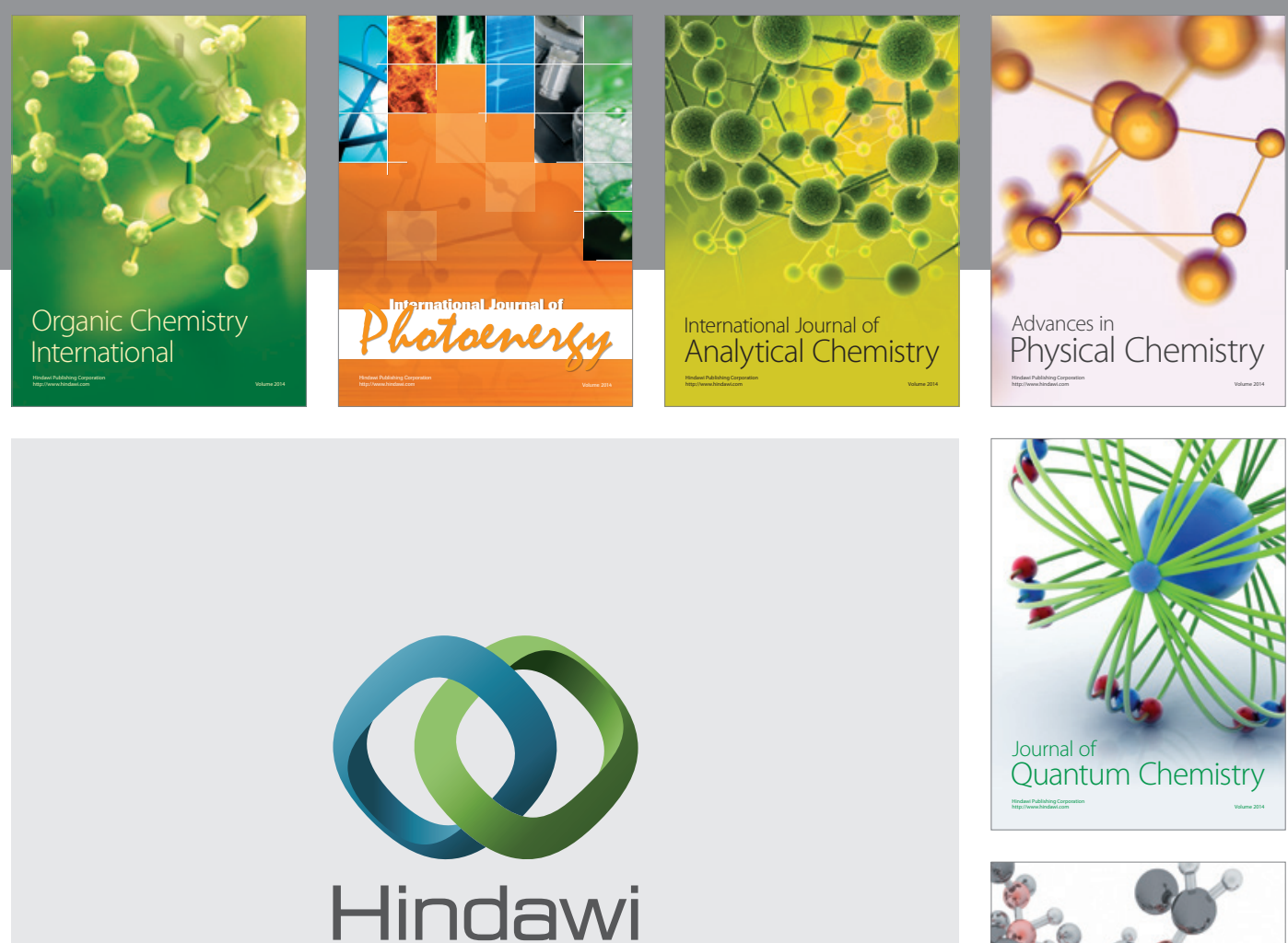

Submit your manuscripts at

http://www.hindawi.com

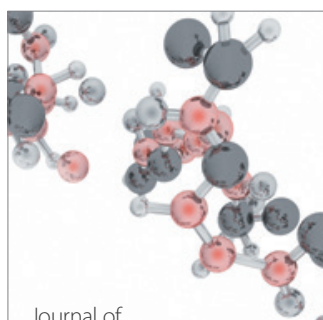

Analytical Methods

in Chemistry

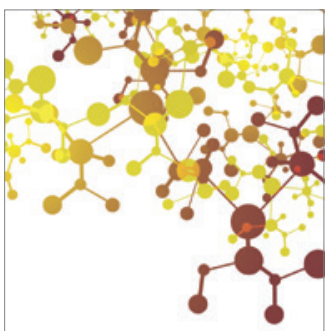

Journal of

Applied Chemistry

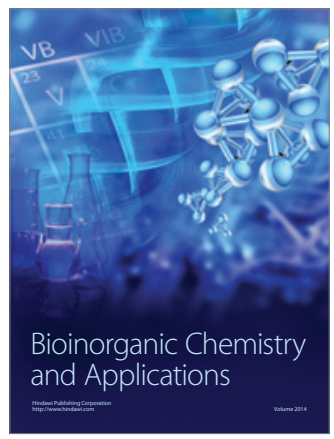

Inorganic Chemistry
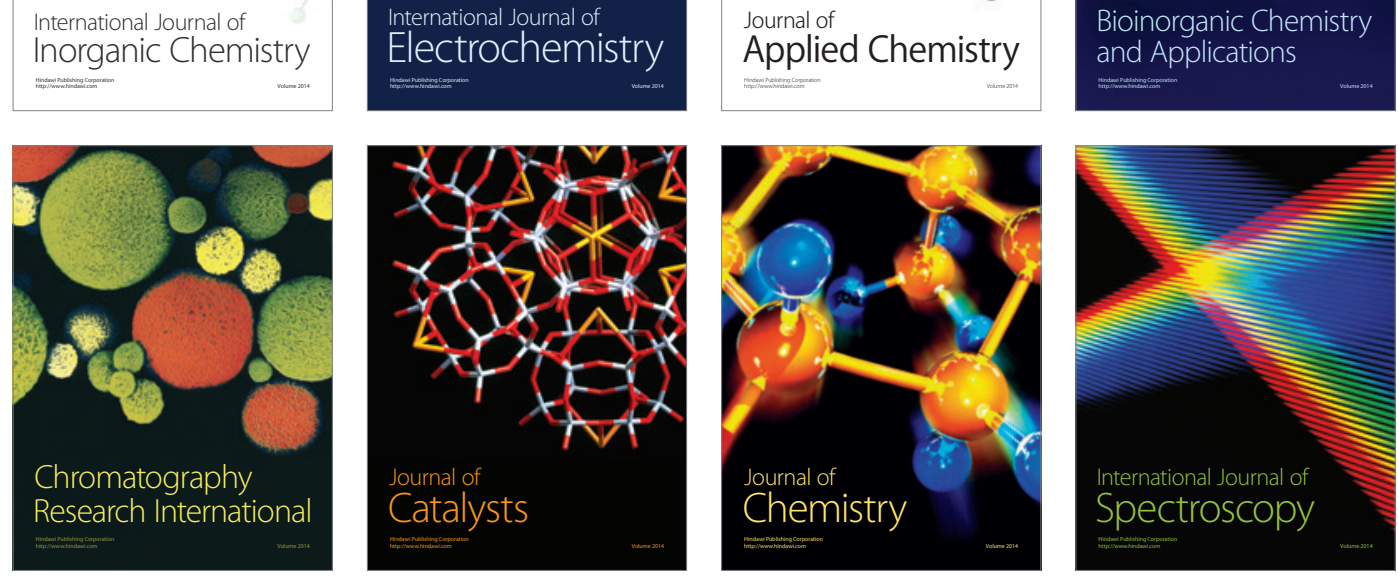